\title{
Cyclometalated Platinum(II) Complex with Strong and Broadband Nonlinear Optical Response
}

\author{
Pin Shao, Yunjing Li, Wenfang Sun ${ }^{*}$ \\ Department of Chemistry and Molecular Biology, North Dakota State University, Fargo, \\ ND 58105
}

*E-mail: Wenfang.Sun@ndsu.edu; Phone: 701-231-6254; Fax: 701-231-8831. 


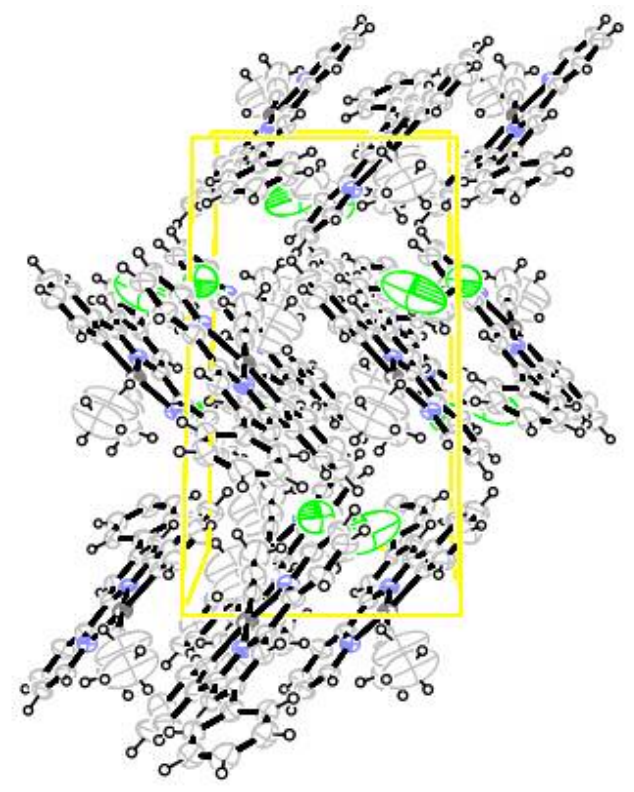

(a)

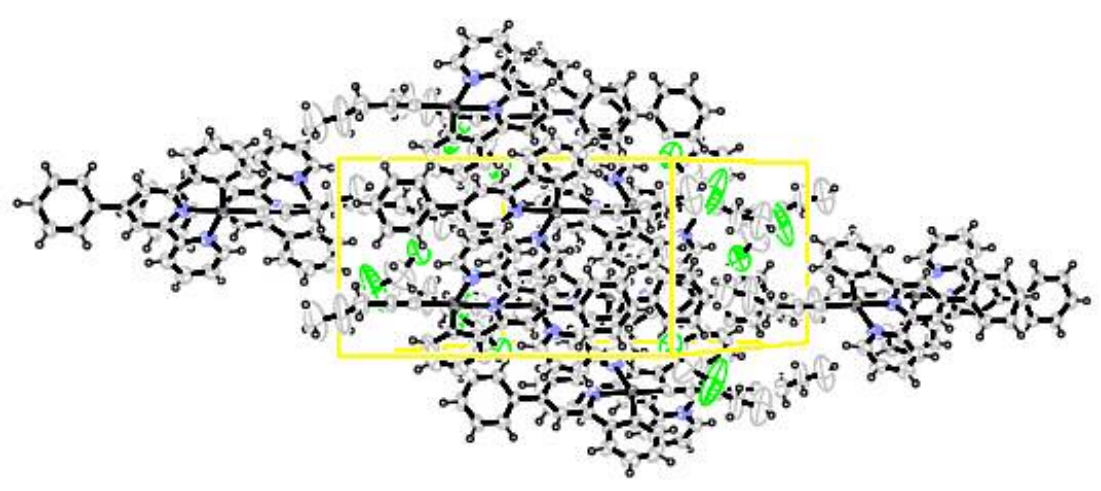

(b)

Figure S1. Crystal packing diagram of 1 with $50 \%$ ellipsoid probability. (a) view normal to (100); (b) view normal to (001). 

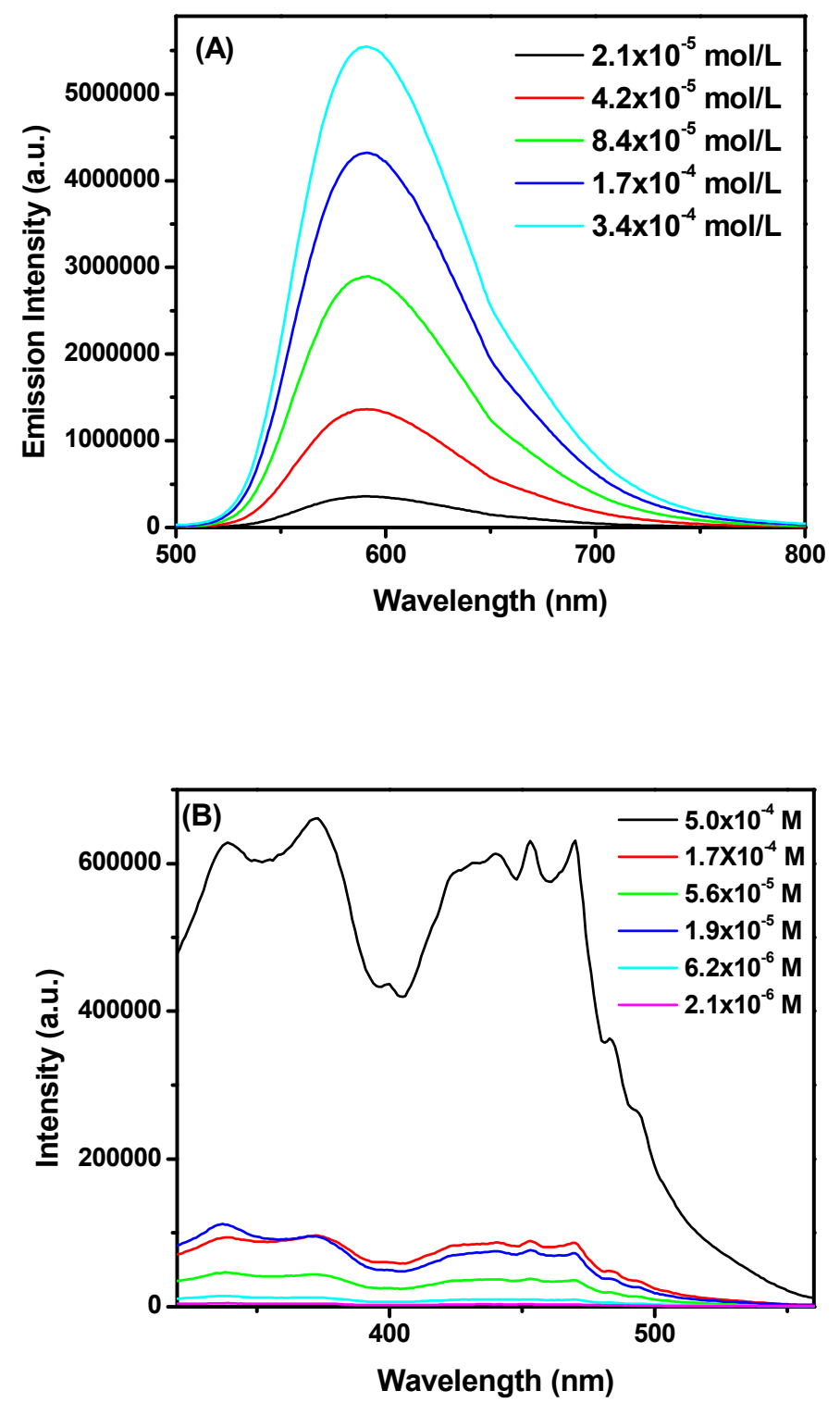

Figure S2. The concentration-dependent emission (A) $\left(\lambda_{\mathrm{ex}}=432 \mathrm{~nm}\right)$ and excitation (B) $\left(\lambda_{\mathrm{em}}=591 \mathrm{~nm}\right)$ spectra of $\mathbf{1}$ in $\mathrm{CH}_{3} \mathrm{CN}$ at room temperature. 


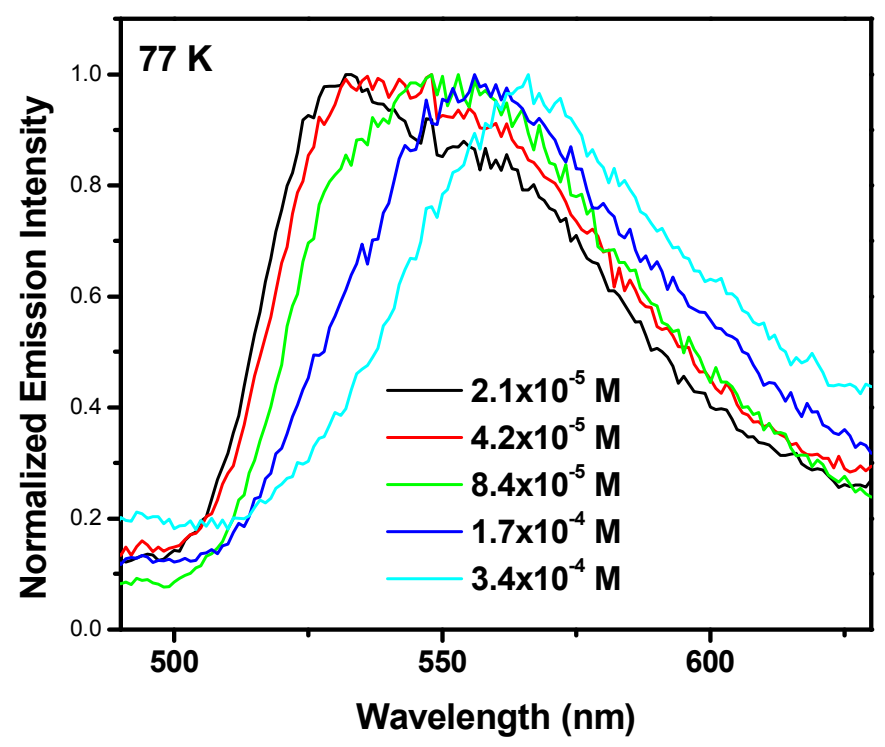

Figure S3. The concentration-dependent emission spectra of $\mathbf{1}$ in $\mathrm{CH}_{3} \mathrm{CN}$ at $77 \mathrm{~K}$. $\left(\lambda_{\mathrm{ex}}=\right.$ $332 \mathrm{~nm})$ 


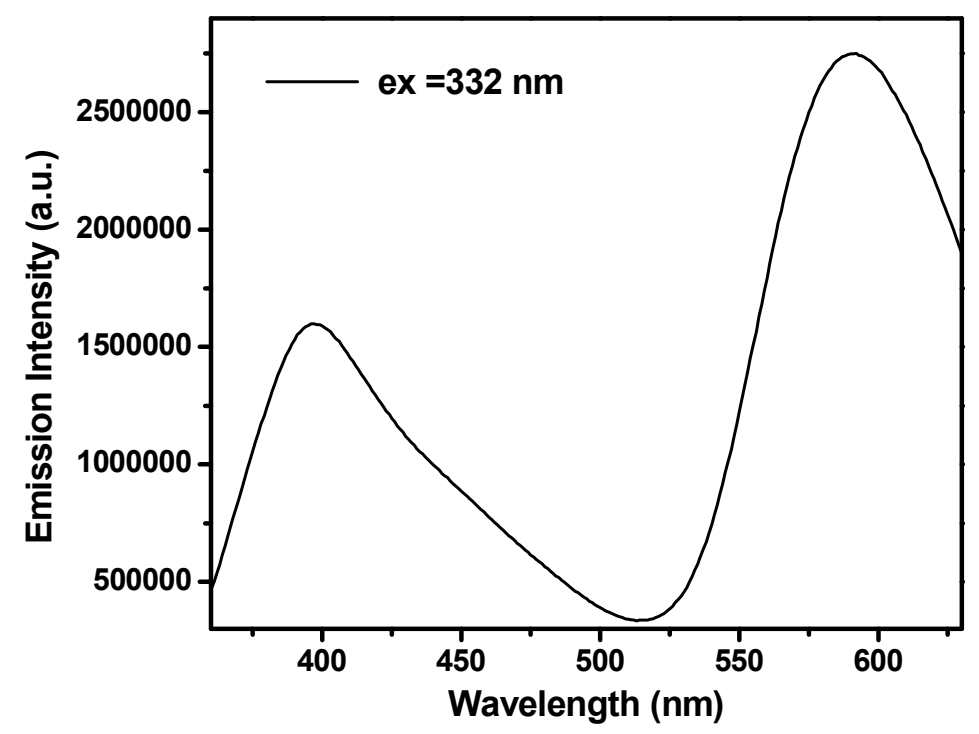

Figure S4. The emission spectrum of 1 in $\mathrm{CH}_{3} \mathrm{CN}$ at a concentration of $1.86 \times 10^{-5}$ $\mathrm{mol} / \mathrm{L}$ at room temperature. $\left(\lambda_{\mathrm{ex}}=332 \mathrm{~nm}\right)$ 


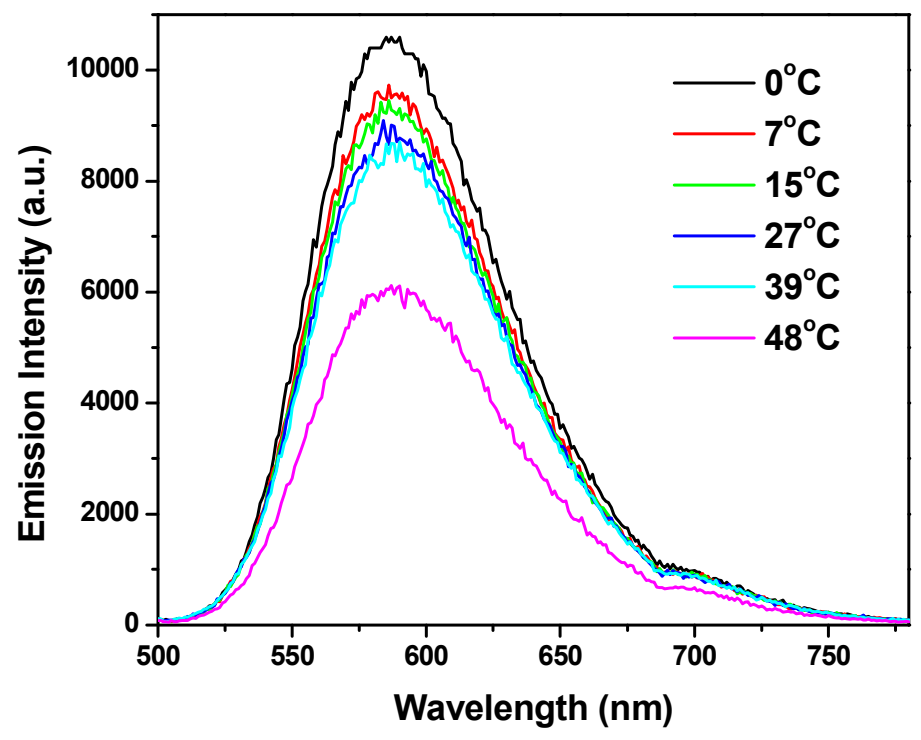

Figure S5. The temperature-dependent emission spectra of 1 in $\mathrm{CH}_{3} \mathrm{CN}$ at a concentration of $3.4 \times 10^{-5} \mathrm{~mol} / \mathrm{L} . \quad\left(\lambda_{\mathrm{ex}}=432 \mathrm{~nm}\right)$ 


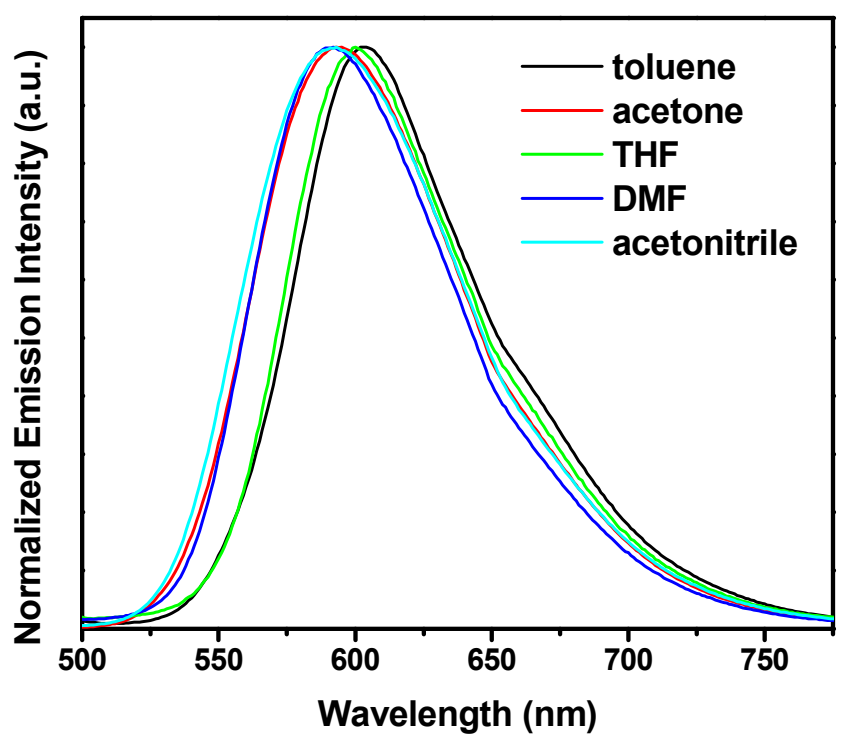

Figure S6. The solvent-dependent emission spectra of 1 at room temperature at a concentration of $3.4 \times 10^{-5} \mathrm{~mol} / \mathrm{L} . \quad\left(\lambda_{\mathrm{ex}}=432 \mathrm{~nm}\right)$ 


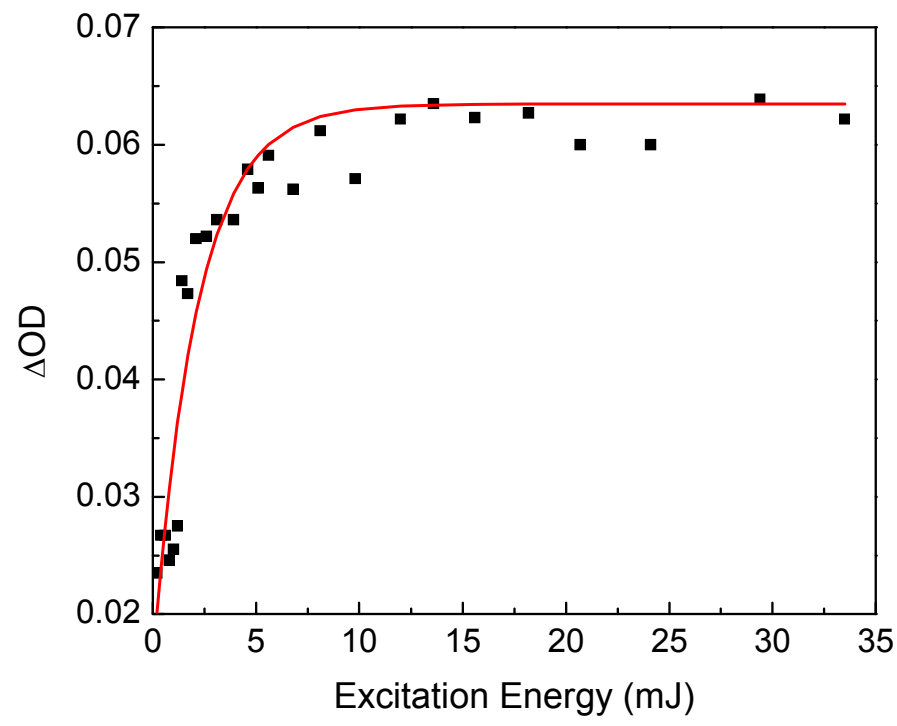

Figure S7. Optical density of transient absorption of 1 at $585 \mathrm{~nm}$ versus excitation energy. 